\title{
Produção e qualidade do meloeiro sob osmocondicionamento da semente e níveis de salinidade da água
}

\section{Yield and quality of the muskmelon under the seed osmoconditioning and water salinity levels}

\author{
Edna Pereira Dantas ${ }^{1}$, Roberto Cleiton Fernandes de Queiroga ${ }^{2}$, Zaqueu Lopes da Silva ${ }^{3}$, Lamartine Eduardo de Assis ${ }^{4}$, \\ Francimalba Francilda de Sousa
}

\begin{abstract}
Resumo: A intensa evaporação, deficiência em drenagem e uso inadequado de fertilizantes têm aumentado os problemas com a salinidade, ocasionando prejuízos no rendimento das culturas. Objetivou-se avaliar a produção e qualidade do meloeiro em função do osmocondicionamento da semente e níveis de salinidade da água. O experimento foi realizado no delineamento de blocos casualizados em parcelas subdivididas do tipo 4 x 2, com quatro repetições. A parcela foi composta por quatro níveis de salinidade da água $\left(0,3,1,0,1,7\right.$ e $\left.2,4 \mathrm{dS} . \mathrm{m}^{-1}\right)$ e nas subparcelas de plantas oriundas de sementes osmocondicionadas (tratadas e não tratadas com solução salina de $\mathrm{NaCl}$ ). A cultivar utilizada foi a Rangers do grupo Cantaloupe, cultivada no espaçamento de $2,0 \times 0,4 \mathrm{~m}$. As características avaliadas foram relacionadas à produção e qualidade dos frutos de melão. $\mathrm{O}$ osmocondicionamento das sementes em solução de $\mathrm{NaCl}$ afetou os componentes de produção do meloeiro em que a massa do fruto foi maior em plantas advindas de sementes tratadas com $\mathrm{NaCl}$. A massa do fruto contribuiu mais do que o número de frutos por planta na formação da produtividade da cultura e que essa diferença foi significativa apenas em condições de baixa salinidade da água de $0,3 \mathrm{dS} \cdot \mathrm{m}^{-1}$. A qualidade do fruto do meloeiro não foi alterada pelo osmocondicionamento da semente com $\mathrm{NaCl}$ e plantas irrigadas com água de salinidade de $2,4 \mathrm{dS} \cdot \mathrm{m}^{-1}$ reduziram sua produção e qualidade de frutos de melão.
\end{abstract}

Palavra-Chaves: Cucumis melo L.; Rendimento; Sólidos solúveis; Tratamento pré-germinativo.

\begin{abstract}
The intense evaporation, drainage deficiency and inadequate use of fertilizers have increased problems with salinity, causing losses in crop yields. It was aimed to evaluate the yield and quality of muskmelon plants due to the priming of seed and levels of water salinity. The experiment was conducted in split type 4 x 2 plots allocated in a randomized block design with four replications. The plot consisted of 4 irrigation water salinity levels $\left(0.3,1.0,1.7\right.$ and $\left.2.4 \mathrm{dS} . \mathrm{m}^{-1}\right)$ and subplots of plants from seed treated and not treated with saline $\mathrm{NaCl}$. It was evaluated the characteristics related to production and quality of melon fruit. The cultivar used was the Rangers of the Cantaloupe group planted in the spacing of $2.0 \times 0.4 \mathrm{~m}$. The priming of the seeds $\mathrm{NaCl}$ solution affected the melon yield components in the fruit mass was higher in plants originated from seeds treated with $\mathrm{NaCl}$. In the formation of productivity, she became apparent the fruit mass contributed more than the number of fruit per plant and this difference was significant only under low water salinity of $0.3 \mathrm{dS} . \mathrm{m}^{-1}$. The quality of the melon fruit was not affected by seed priming with $\mathrm{NaCl}$ and plants irrigated with saline water of $2.4 \mathrm{dS} . \mathrm{m}^{-1}$ reduced their production and fruit quality of melon.
\end{abstract}

Key words: Cucumis melo L.; Yield; Soluble solids; Re-germination treatment.

\footnotetext{
*Autor para correspondência

Recebido para publicação em 25/11/2017; aprovado em 20/12/2017

${ }^{1}$ Mestre em Horticultura Tropical, Universidade Federal de Campina Grande, Centro de Ciências e Tecnologia Agroalimentar, Pombal; (83) 9655-0299, ednadantaspereira@gmail.com.

${ }^{2}$ Doutor em Fitotecnia, Universidade Federal de Campina Grande, Centro de Ciências e Tecnologia Agroalimentar, Pombal, robertoqueiroga@ccta.ufcg.edu.br ${ }^{3}$ Graduando em Agronomia, Universidade Federal de Campina Grande, Centro de Ciências e Tecnologia Agroalimentar, Pombal, zaqueulopes@ yahoo.com.br ${ }^{4}$ Graduando em Agronomia, Universidade Federal de Campina Grande, Centro de Ciências e Tecnologia Agroalimentar, Pombal, lamartine_agro@hotmail.com

${ }^{5}$ Graduando em Agronomia, Universidade Federal de Campina Grande, Centro de Ciências e Tecnologia Agroalimentar, Pombal, malbah_senna@hotmail.com
} 


\section{INTRODUÇÃO}

O meloeiro é uma olerícola pertencente à família das Cucurbitáceas que produz frutos que se destacam devido ao sabor e alto valor nutritivo se constituindo em uma das frutas frescas mais exportadas pelo Brasil (NASCIMENTO NETO et al., 2012). A região nordeste do Brasil apresenta grande relevância econômica em decorrência do cultivo dessa olerícola apresentarem excelente valor de mercado e ser de fácil adaptabilidade as condições de clima e solo (PEREIRA et al., 2012).

A produção dessa hortaliça de fruto nas localidades do semiárido nordestino só é possível por meio da prática da irrigação. Todavia, a disponibilidade de águas de baixa salinidade, possui custo elevado com volume explorável limitado, já as águas de poços rasos, possuem custo menor e com maior potencial de uso, embora possam apresentar maior concentração de sais, podendo reduzir o rendimento das culturas (QUEIROGA et al., 2006). Nessas áreas, a salinização é potencializada pela intensa evaporação, a deficiência em drenagem e o próprio uso de fertilizantes, prejudicando o rendimento das culturas (MEDEIROS et al., 2011).

Os efeitos da salinidade em sementes e plantas têm sido discutidos e podem causar limitações em todos os estádios de crescimento e desenvolvimento, comprometendo eventos fisiológicos que vão desde a germinação à produção (PINHEIRO, 2015). Assim, o excesso de sais no solo reduz a disponibilidade de água para as plantas, além de provocar desequilíbrio nutricional e toxicidade de íons específicos na planta a ponto de comprometer os rendimentos e a qualidade da produção (TERCEIRO NETO et al., 2013).

Uma tecnologia que pode ser utilizada para se produzir, economicamente, em condições de salinidade é a preparação da semente através do osmocondicionamento. O condicionamento fisiológico tem sido utilizado para reduzir o tempo de germinação, aumentar a germinabilidade, a uniformidade e vigor das plântulas. Dentre as técnicas de condicionamento fisiológico o osmocondicionamento tem sido a mais utilizada (PINHEIRO, 2015).

Essa técnica consiste no pré-tratamento, onde as sementes são imersas em solução osmótica, sob tempo e temperatura determinados (SIVITREPE et al., 2003). Segundo os mesmos autores, em geral, as plantas não desenvolvem tolerância a sais, a menos que elas cresçam em condições salinas; adicionalmente, níveis elevados de sais na água promovem a redução da taxa de crescimento das plantas, resultando em folhas menores e em menor número.

Objetivando estudar procedimentos para o condicionamento fisiológico e verificar suas relações com o desempenho das sementes e plantas em campo na cultura do pepino, Lima e Marcos Filho (2009), constataram que o osmocondicionamento em papel embebido em solução de PEG -0,2 MPa, revelou-se eficiente, afetando mais claramente a velocidade do que a porcentagem de germinação dos lotes avaliados; também verificaram que o condicionamento fisiológico permite a formação de mudas vigorosas de pepino, no entanto, esses benefícios não se estendem até a produção de frutos em campo.

Esse método tem sido mais utilizado na produção de mudas de hortaliças e pouco se sabe sobre seus efeitos sobre a produção final da planta. Assim, podemos inferir que a técnica de condicionamento fisiológico de sementes poderá trazer avanços na produção e na qualidade de frutos do meloeiro por meio da maior resistência da plântula no campo quando expostas as adversidades ambientais como salinidade da água ou do solo.

Objetivou-se avaliar a produção e a qualidade de frutos de melão em função do osmocondicionamento das sementes e níveis de salinidade da água nas condições do semiárido paraibano.

\section{MATERIAL E MÉTODOS}

O experimento foi realizado na Universidade Federal de Campina Grande no Centro de Ciências e Tecnologia Agroalimentar, em Pombal - PB, durante o período de julho a outubro de 2015. O município apresenta as coordenadas geográficas (6 $6^{\circ} 46^{\prime} 13^{\prime}$ ' S, 37 48'06” O). O clima da região, na classificação climática de Koppen adaptada ao Brasil, é do tipo BSh, considerado clima semiárido quente e seco. O solo da área experimental é do tipo Neossolo Flúvico (EMBRAPA, 2008).

$\mathrm{O}$ experimento foi realizado no delineamento de blocos casualizados em parcelas subdivididas do tipo 4 x 2, com quatro repetições. A parcela foi composta por quatro níveis de salinidade da água de irrigação $\left(0,3,1,0,1,7\right.$ e 2,4 dS.m $\left.{ }^{-1}\right)$ e nas subparcelas foram formadas por plantas oriundas de sementes osmocondicionadas (sementes tratadas e não tratadas com solução salina de $\mathrm{NaCl}$ ).

O solo foi preparado por meio de uma aração e gradagem com posterior levantamento de leiras, implantação do sistema de irrigação do tipo gotejamento e adubação de plantio. Realizou-se a cobertura do solo com o mulching utilizando filme de polietileno dupla face (preto e prateado).

Foi realizada adubação orgânica na dosagem de 10 t.ha $^{-1}$ a base seca como forma de melhoras as características físicas e químicas do solo. Adicionalmente, foi utilizado de forma suplementar em plantio os seguintes adubos: $160 \mathrm{~kg} \cdot \mathrm{ha}^{-1} \mathrm{de}$ superfosfato simples sendo $100 \%$ em fundação, juntamente com $10 \%$ do $\mathrm{N}$ e $\mathrm{K}_{2} \mathrm{O}$ da dose recomendada, equivalentes a 17 e $10 \mathrm{~kg} \cdot \mathrm{ha}^{-1}$ na forma de ureia e cloreto de potássio, respectivamente.

$\mathrm{Na}$ adubação de cobertura, foram utilizados o $\mathrm{N}$ e o $\mathrm{K}_{2} \mathrm{O}$ nas doses de 153 e $90 \mathrm{~kg} \cdot \mathrm{ha}^{-1}$ correspondentes aos $90 \%$ restante, aplicados via fertirrigação, com frequência semanal durante oito semanas, iniciando-se três dias após o transplantio. Em cada semana foram aplicadas, respectivamente, as seguintes $\%$ de cada nutriente: $1^{\mathrm{a}}=5,0 \%$ de $\mathrm{N}$ e $5,0 \%$ de $\mathrm{K}_{2} \mathrm{O} ; 2^{\mathrm{a}}=8,0 \%$ de $\mathrm{N}$ e $8,0 \%$ de $\mathrm{K}_{2} \mathrm{O} ; 3^{\mathrm{a}}$ $=10,0 \%$ de $\mathrm{N}$ e $10,0 \%$ de $\mathrm{K}_{2} \mathrm{O} ; 4^{\mathrm{a}}=12,0 \%$ de $\mathrm{N}$ e $12,0 \%$ de $\mathrm{K}_{2} \mathrm{O} ; 5^{\mathrm{a}}=15,0 \%$ de $\mathrm{N}$ e $15,0 \%$ de $\mathrm{K}_{2} \mathrm{O} ; 6^{\mathrm{a}}=20,0 \%$ de $\mathrm{N}$ e $20,0 \%$ de $\mathrm{K}_{2} \mathrm{O} ; 7^{\mathrm{a}}=12,0 \%$ de $\mathrm{N}$ e $12,0 \%$ de $\mathrm{K}_{2} \mathrm{O}$ e $8^{\mathrm{a}}=8,0$ $\%$ de $\mathrm{N}$ e $8,0 \%$ de $\mathrm{K}_{2} \mathrm{O}$.

No dia 06 de julho de 2015 parte das sementes foram colocadas para embeber em solução salina $(\mathrm{NaCl})$ com concentração de $9,73 \mathrm{dS} \cdot \mathrm{m}^{-1}$ por $10 \mathrm{~h}$ (QUEIROGA et al., 2006) sendo esses os melhores resultados encontrado com o pré-ensaio de sementes de melão na embebição das sementes e a outra parte em água de abastecimento com concentração de $0,3 \mathrm{dS} . \mathrm{m}^{-1}$.

A cultivar de meloeiro utilizada foi a 'Rangers' do grupo Cantaloupe. O transplantio foi realizado com as mudas colocadas no espaçamento $2,0 \times 0,4 \mathrm{~m}$, com uma planta por cova.

A semeadura foi realizada no dia 06 de julho de 2015, em bandejas de poliestireno de 128 células contendo uma 
semente por célula (tratadas ou não) em solução salina de $\mathrm{NaCl}$. A cultivar de meloeiro utilizada foi a 'Rangers' do grupo Cantaloupe. O substrato utilizado foi o Tropstrato HA hortaliças.

O transplantio das mudas ocorreu aos quinze dias após a semeadura, em 21 de julho de 2015, quando as mudas já estavam com a segunda folha definitiva emitida.

$\mathrm{Na}$ cobertura das plantas foi usado o agrotêxtil sustentado com a colocação dos arcos de polietileno rígido reciclado, a uma altura de $50 \mathrm{~cm}$ do solo na parte central. Foi usado o agrotêxtil branco de polipropileno, com largura de $1,38 \mathrm{~m}$ e gramatura de $15 \mathrm{~g} . \mathrm{cm}^{2}$ sendo colocado e fixado nas laterais formando um túnel.

A irrigação foi realizada com solução com diferentes níveis de salinidade, obtida através da adição de $\mathrm{NaCl}$ a água de irrigação $\left(\mathrm{S} 1=0,3 ; \mathrm{S} 2=1,0 ; \mathrm{S} 3=1,7\right.$ e S4 = 2,4 dS. $\left.\mathrm{m}^{-1}\right)$ e monitorada com o auxílio de um condutivímetro portátil (Sammar CD-840). As lâminas de irrigações foram aplicadas de acordo com estágio de desenvolvimento da cultura.

As plantas foram conduzidas de acordo com os tratamentos sugeridos; a retirada do agrotêxtil foi realizada no dia 12 de agosto de 2015 quando as plantas estavam com 22 dias após o transplantio (DAT) e no início da floração da cultura para que houvesse a polinização por meio das abelhas.

$\mathrm{Na}$ ocasião da retirada do agrotêxtil, foi realizada capina manual em cada tratamento e controle fitossanitário com fungicida e inseticida registrado para a cultura. Foram realizadas três aplicações, sendo uma no momento da retirada do agrotêxtil, a segunda aos 15 dias após a primeira aplicação e a última com oito dias antes da colheita em razão da ocorrência de mosca branca na fase final do experimento. As aplicações dos produtos foram realizadas no final da tarde, evitando a aplicação de qualquer tipo de defensivo durante a manhã quando havia maior presença de abelhas.

As colheitas foram realizadas entre 22 e 25 de setembro de 2015. Os frutos foram colhidos quando o pedúnculo apresentava-s rachado e com rendilhamento uniforme, sendo esse um indicativo confiável do ponto de colheita desta cultivar. $\mathrm{O}$ ciclo da cultura durou 80 dias, da semeadura até o final da colheita.

As características avaliadas foram obtidas da seguinte forma: o número de frutos por planta foi obtido por meio da contagem de frutos por parcela em cada tratamento e em todas as plantas úteis que totalizavam oito; a massa do fruto foi obtida por meio da razão entre a produção da parcela pelo número de frutos na parcela, em kg.fruto ${ }^{-1}$; a produtividade total do melão foi realizada pelo somatório de todas as colheitas realizadas na parcela e, posteriormente estimados para 1 ha, sendo expressa em $\mathrm{Mg}_{\text {. ha }}{ }^{-1}$.

As características de qualidade avaliadas em laboratório foram provenientes de uma amostra de quatro frutos por unidade experimental totalizando dezesseis frutos por tratamento, sendo que em cada fruto de melão foi realizado um corte no sentido longitudinal, a fim de se obter as seguintes características: firmeza da polpa, por meio da utilização do penetrômetro manual com ponteira cilíndrica de 12 mm de diâmetro; espessura da polpa, adquirido por duas leituras, na região equatorial do fruto, utilizando um paquímetro digital $(\mathrm{cm})$.

Da mesma amostra de quatro frutos foram avaliados: sólidos solúveis (\%) e acidez titulável, em amostras de fatias de frutos retiradas no sentido longitudinal e homogeneizadas em centrífuga de frutas para a obtenção do suco; os sólidos solúveis (SST) foram determinados por meio de refratômetro digital, obtendo-se os valores em porcentagem. Para acidez titulável (AT) (porcentagem de ácido cítrico) foi utilizada uma alíquota de $2 \mathrm{~mL}$ de suco, em duplicata, a qual foi adicionado $50 \mathrm{~mL}$ de água destilada e duas gotas fenolftaleína alcoólica a $1 \%$ e, em seguida, procedeu-se a titulação com solução de $\mathrm{NaOH} 0,1 \mathrm{~N}$ até o ponto de viragem; com a mesma amostra, foi determinado o índice de maturação por meio da razão entre sólidos solúveis e acidez titulável.

Os dados obtidos foram submetidos à análise de variância pelo teste F, usando-se o software SAEG 9.0. Para o osmocondicionamento da semente em $\mathrm{NaCl}$ foi realizado o teste de Tukey ao nível 5\% de probabilidade e para os níveis de salinidade da água foi realizado a análise de regressão no software Table Curve 2D.

\section{RESULTADOS E DISCUSSÃO}

Foi observada interação significativa dos fatores níveis de salinidade $\mathrm{x}$ osmocondicionamento da semente com $\mathrm{NaCl}$ sob o número de frutos por planta e a produtividade, no entanto, para a massa do fruto houve efeito significativo isolado apenas do osmocondicionamento da semente com $\mathrm{NaCl}(\mathrm{p}<0,05)$.

Para a massa do fruto foi encontrado maior valor, com média de 1,00 kg.fruto ${ }^{-1}$, quando as plantas foram oriundas de sementes osmocondicionadas com $\mathrm{NaCl}$ (Tabela 1).

Tabela 1. Valores médios de massa do fruto, número de frutos por planta e da produtividade total de meloeiro em função do tratamento da semente com e sem NaCl, Pombal, Paraíba.

\begin{tabular}{|c|c|c|c|c|c|c|c|c|c|}
\hline \multirow[t]{3}{*}{$\begin{array}{l}\text { Tratamento } \\
\text { semente }\end{array}$} & \multirow[t]{3}{*}{$\begin{array}{l}\text { Massa do } \\
\text { fruto } \\
\left(\mathrm{kg}_{\text {fruto }}{ }^{-1}\right)\end{array}$} & \multicolumn{4}{|c|}{ Número de frutos por planta } & \multicolumn{4}{|c|}{ Produtividade total $\left(\mathrm{Mg} \cdot \mathrm{ha}^{-1}\right)$} \\
\hline & & \multicolumn{4}{|c|}{ Nível de salinidade $\left(\mathrm{dS} . \mathrm{m}^{-1}\right)$} & \multicolumn{4}{|c|}{ Nível de salinidade $\left(\mathrm{dS} . \mathrm{m}^{-1}\right)$} \\
\hline & & 0,3 & 1,0 & 1,7 & 2,4 & 0,3 & 1,0 & 1,7 & 2,4 \\
\hline $\mathrm{Na}$ presença de $\mathrm{NaCl}$ & $1,006 \mathrm{a}$ & $2,2 \mathrm{~b}$ & $2,5 \mathrm{a}$ & $2,4 \mathrm{a}$ & $2,3 \mathrm{a}$ & $36,70 \mathrm{a}$ & $32,30 \mathrm{a}$ & 29,49 a & $25,27 \mathrm{a}$ \\
\hline $\mathrm{Na}$ ausência de $\mathrm{NaCl}$ & $0,895 \mathrm{~b}$ & $2,8 \mathrm{a}$ & $2,6 \mathrm{a}$ & $2,4 \mathrm{a}$ & $2,3 \mathrm{a}$ & $24,98 \mathrm{~b}$ & $28,51 \mathrm{a}$ & $26,55 \mathrm{a}$ & $23,78 \mathrm{a}$ \\
\hline $\mathrm{CV}(\%)$ & 9,67 & 6,52 & & & & 10,33 & & & \\
\hline
\end{tabular}

*Médias seguidas pela mesma letra nas colunas não diferem entre si ao nível de $5 \%$ de probabilidade pelo teste Tukey.

Nesse sentido, a ação prévia do osmocondicionamento pode ter favorecido a tolerância das plantas em condições adversas independentemente do nível de salinidade da água aplicada. A tolerância ao estresse é uma das principais vantagens do osmocondicionamento por conferir as plantas maior tolerância à deficiência hídrica e ao aumento da concentração salina, evidenciados frequentemente na literatura.

No número de frutos por planta foi evidenciado que o menor nível de salinidade de $0,3 \mathrm{dS} . \mathrm{m}^{-1}$ expressou valores 
médios significativos em plantas oriundas de sementes não tratadas com $\mathrm{NaCl}$ (Tabela 1). Em condições mais extremas de salinidade da água de irrigação obtida no nível de 2,4 $\mathrm{dS} . \mathrm{m}^{-1}$, ficou notório que o efeito das sementes tratadas com $\mathrm{NaCl}$ se iguala a das sementes não tratadas.

$\mathrm{Na}$ produtividade total verificou-se que uma resposta distinta da encontrada para a massa do fruto, provavelmente, em razão da massa do fruto ter representado mais para a formação da produtividade da cultura do que propriamente o número de frutos por planta.

Segundo Bruce et al. (2007), um estresse inicial provocado pelo condicionamento fisiológico favorece uma resposta de tolerância para um futuro estresse que a planta possa sofrer. De acordo com os mesmos autores, as plantas são capazes de expressar um tipo de "memória", também chamada de "impressão do estresse" e, essa impressão, é comumente traduzida por modificações genéticas e bioquímicas induzidas por uma primeira exposição ao estresse que aumenta a resistência a uma condição adversa subsequente.

Verificou-se que, independente do tratamento da semente com $\mathrm{NaCl}$, houve uma redução na massa do fruto com o aumento do nível de salinidade da água até $2,4 \mathrm{dS} . \mathrm{m}^{-1}$ (Figura 1).

Com isso, a redução observada na massa do fruto foi de $6,7 \%$. Assim, as plantas em campo demonstraram que ao se aumentar as condições adversas de salinidade a que foram submetidas, os frutos tendem a diminuir sua massa, restringindo o desenvolvimento do peso do fruto.

Cabe destacar ainda, que o efeito negativo da salinidade na massa do fruto como constatado, foi ocasionado provavelmente pela dificuldade de absorção de água pelas plantas como também pela competição entre íons, ocasionando a redução da absorção de água pelas plantas, o que consequentemente afetou o de aumento de massa do fruto. Segundo Pacheco et al. (2012), a salinidade reduz o potencial osmótico do meio e prolonga o tempo necessário para a absorção de água pelas plantas.

Figura 1. Função de resposta ajustada para a massa do fruto de melão em função dos níveis de salinidade da água, Pombal, Paraíba

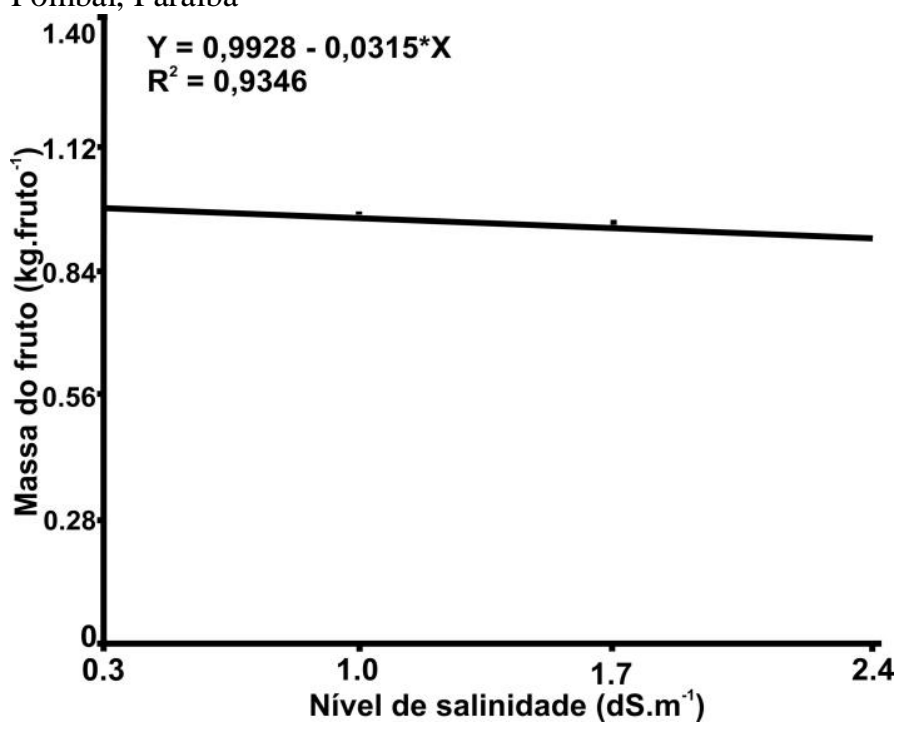

Silva et al. (2014), afirma que a produção de abobora sob diferentes níveis de águas salinas, resultou em maior massa média dos frutos totais na condutividade de $1,5 \mathrm{dS} . \mathrm{m}^{-1}$ seguido de um decréscimo com o contínuo aumento da condutividade elétrica da água de irrigação.

Em sementes osmocondicionadas com $\mathrm{NaCl}$, obteve-se o valor máximo para o número de frutos por planta de 2,5 no nível de salinidade da água de $0,90 \mathrm{dS} . \mathrm{m}^{-1}$, com posterior redução do número de frutos por planta a medida que se aumentou o nível de salinidade da água até $2,4 \mathrm{dS} . \mathrm{m}^{-1}$ (Figura 2A).

Figura 2. Função de resposta ajustada para o número de frutos em plantas oriundas de sementes tratadas (A) e não tratadas (B) com solução de $\mathrm{NaCl}$ em função dos níveis de salinidade da água, Pombal, Paraíba.

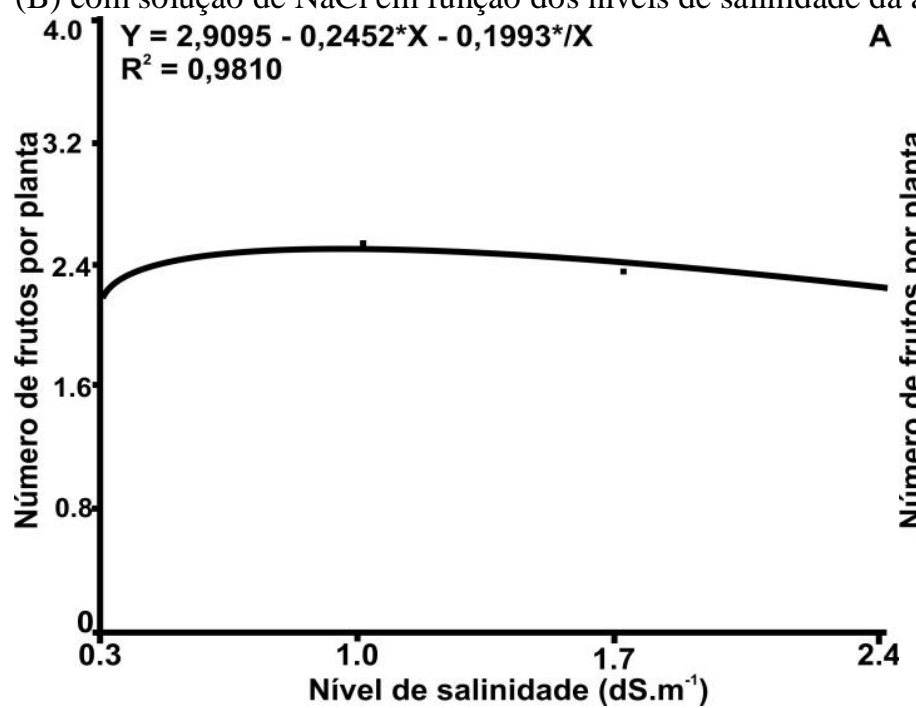

Nesse caso, a redução foi de $8,9 \%$ no número de frutos por planta. Por outro lado, nas plantas cujas sementes não foram osmocondicionadas com $\mathrm{NaCl}$, obteve-se uma resposta linear decrescente com o aumento do nível de salinidade da água até 2,4 dS.m ${ }^{-1}$ (Figura 2B). Assim, o aumento da

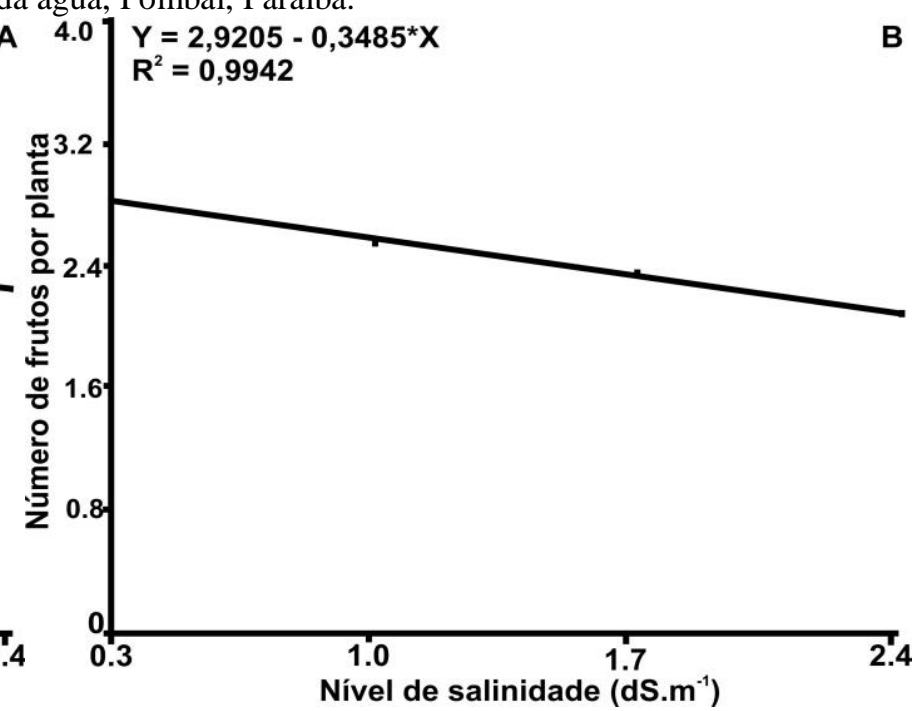

condutividade elétrica da água proporcionou uma redução de $25,9 \%$ no número de frutos por planta.

Dessa forma fica evidenciado que tanto em sementes tratadas quanto não tratadas com solução de $\mathrm{NaCl}$, há redução no número de frutos por planta com o aumento do nível de salinidade da água. No entanto, essa redução no número de 
frutos na planta foi menor em plantas oriundas de sementes osmocondicionadas com $\mathrm{NaCl}$ que foi de apenas 8,9\%. Esse fato pode está relacionado ao tratamento pré germinativo em que se fez uso do osmocondicionamento nas sementes de melão.

Um dos fatos que pode ter contribuído também para a redução do número de frutos por planta com o aumento do nível de salinidade da água de irrigação é o abortamento de flores e/ou frutos, trazendo consequências na diminuição dos frutos por planta. Pereira et al. (2012), afirma que a salinidade elevada do solo durante o período de floração reduz o número de frutos na planta.

Estes resultados estão de acordo com os observados por Silva et al. (2005), trabalhando com meloeiro em diferentes níveis de água de salinidade, onde verificaram que o número de frutos total no híbrido 'Trusty' decresceu linearmente, obtendo diferenças percentuais de 13 e $26 \%$ nas salinidades de 2,5 e 4,4 dS. $\mathrm{m}^{-1}$, respectivamente. Terceiro Neto et al. (2013), encontraram para o número de frutos comerciais e totais redução de valores com o aumento da salinidade da água de irrigação e Medeiros et al. (2011), em melão Pele de Sapo híbrido 'Medellín' cultivado com diferentes salinidades da água, verificaram que o número de frutos totais por planta reduziu em $8,7 \%$ com o aumento dos níveis de salinidade da água de irrigação.

Para a produtividade total, apenas na condutividade da água de $0,3 \mathrm{dS} . \mathrm{m}^{-1}$ observa-se uma tendência de maior rendimento em plantas provenientes de sementes osmocondicionadas com $\mathrm{NaCl}$ quando comparadas com sementes não osmocondicionadas (Tabela 1). Essa resposta foi diferente da observada no número de frutos por planta provavelmente em função da maior contribuição da massa do fruto na formação da produtividade da cultura do que propriamente do número de frutos na planta. Outro fato é que os frutos de plantas oriundas de sementes osmocondicionadas com $\mathrm{NaCl}$ apresentaram com maior massa e, consequentemente, menor número em razão do equilíbrio fonte dreno na planta.

Considerando os efeitos dos níveis de salinidade da água de irrigação sob a produtividade da cultura verifica-se uma resposta linear decrescente em plantas oriundas de sementes osmocondicionadas com $\mathrm{NaCl}$ com uma queda no valor estimado máximo de 36,51 para 25,37 Mg.ha ${ }^{-1}$, ou seja, $30,4 \%$ quando se passou do nível de 0,3 para $2,4 \mathrm{dS} . \mathrm{m}^{-1}$ (Figura 3A).

Figura 3. Função de resposta ajustada para produtividade total em plantas oriundas de sementes tratadas (A) e não tratadas (B) com solução de $\mathrm{NaCl}$ em função dos níveis de salinidade da água, Pombal, Paraíba.

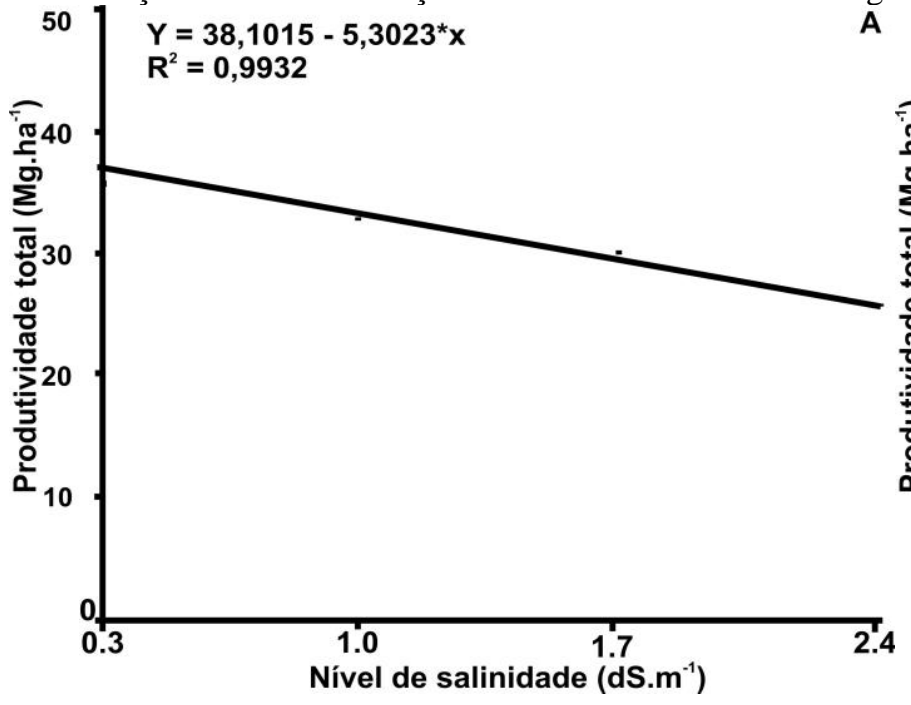

Em plantas oriundas de sementes que não passaram pelo osmocondicionamento observou-se uma resposta quadrática com valor estimado máximo de 27,97 Mg.ha ${ }^{-1}$ no nível de salinidade da água de $1,23 \mathrm{dS} . \mathrm{m}^{-1}$ (Figura 3B); a partir desse ponto houve uma redução estimada para $23,54 \mathrm{Mg}$ ha $^{-1}$, o que corresponde a $15,8 \%$.

Apesar disso, plantas advindas de sementes osmocondicionadas quando compradas com aquelas advindas de sementes não osmocondicionadas em solução de $\mathrm{NaCl}$ apresentaram tendência a ter um valor absoluto maior para produtividade total independentemente do nível de salinidade da água. Isso sugere que os níveis mais altos de salinidade da água em plantas oriundas de sementes não tratadas com solução de $\mathrm{NaCl}$ induzem menor produção de frutos, afetando negativamente o rendimento final da cultura.

De acordo com os resultados obtidos nesse experimento, a principal causa da redução da produtividade total em níveis de salinidade da água mais elevados foi devido à diminuição

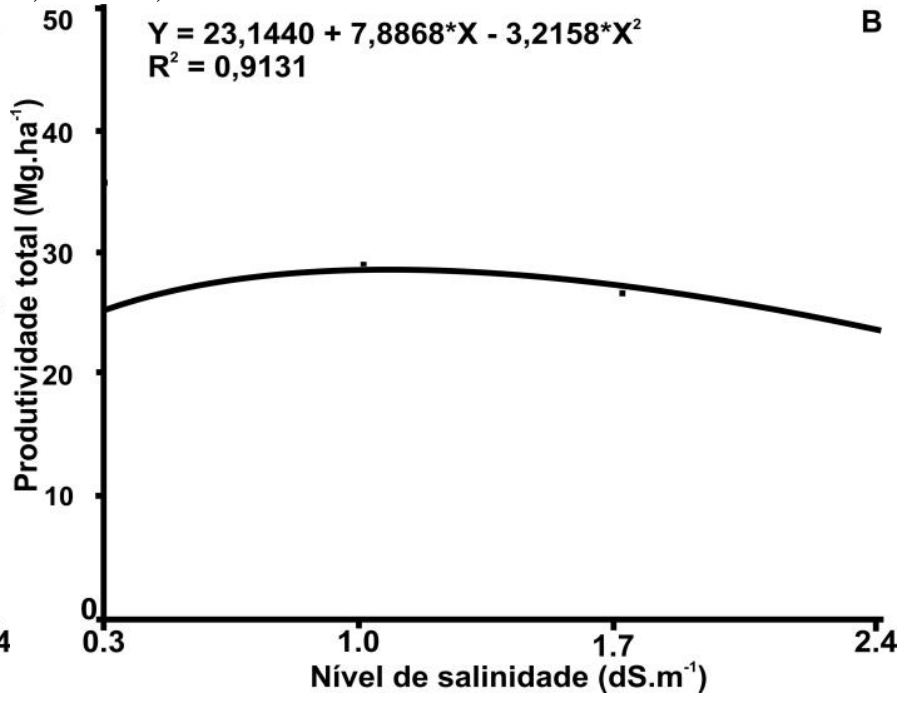

do número de frutos por planta e da massa do fruto. Freitas et al. (2014), encontraram resultados semelhantes para produção total de melão submetidos ao diferentes níveis de salinidade ao verificarem que houve ajuste significativo do modelo linear e que o aumento da salinidade diminuiu os valores dos componentes da produção linearmente. Os mesmos autores afirmam que o decréscimo da produtividade observado foi 4,24 Mg.ha ${ }^{-1}$ por acréscimo unitária da condutividade elétrica da água de irrigação para a produção total.

Concordando com Medeiros et al. (2011), a produtividade total do melão Pele de Sapo híbrido 'Medellín' foi influenciada negativamente pelo aumento dos níveis de salinidade, obtendo-se o maior valor de 57,73 Mg.ha ${ }^{-1}$ com o nível de salinidade da água de $0,54 \mathrm{dS} . \mathrm{m}^{-1}$. O incremento unitário da salinidade acima do menor nível $\left(0,54\right.$ dS.m $\left.{ }^{-1}\right)$ proporcionou redução de $7,8 \%$ para a produção comercial. Nesse trabalho foi encontrado resultado diferente em que a principal causa da redução da produtividade de frutos foi à 
diminuição no número de frutos por planta quando os níveis de sais na água ficaram elevados, já que a redução na massa não foi significativa.

Não foi observada diferença significativa na interação dos fatores níveis de salinidade $\mathrm{x}$ osmocondicionamento da semente com $\mathrm{NaCl}$ para nenhuma das características de qualidade dos frutos do meloeiro $(p \geq 0,05)$.

Adicionalmente, podemos afirmar que o osmocondicionamento da semente com $\mathrm{NaCl}$ não refletiu em diferenças significativas nas características de qualidade do fruto (Tabela 2).

Tabela 2. Valores médios de comprimento, diâmetro, índice de formato dos frutos, firmeza e espessura da polpa de frutos de melão em função do tratamento da semente com e sem NaCl. Pombal, Paraíba.

\begin{tabular}{|c|c|c|c|c|c|}
\hline $\begin{array}{l}\text { Tratamento } \\
\text { semente }\end{array}$ & Firmeza $(\mathrm{N})$ & $\begin{array}{ll}\text { Espessura } & \text { da } \\
\text { polpa }(\mathrm{cm}) & \end{array}$ & $\begin{array}{l}\text { Sólidos } \\
\text { solúveis (\%) }\end{array}$ & $\begin{array}{l}\text { Acidez total } \\
\text { (\% de ácido cítrico) }\end{array}$ & $\begin{array}{l}\text { Índice de maturação } \\
\text { do fruto }\end{array}$ \\
\hline $\mathrm{Na}$ presença de $\mathrm{NaCl}$ & $25,53 \mathrm{a}$ & $4,12 \mathrm{a}$ & $8,88 \mathrm{a}$ & $0,090 \mathrm{a}$ & $110,96 \mathrm{a}$ \\
\hline $\mathrm{Na}$ ausência de $\mathrm{NaCl}$ & $24,65 \mathrm{a}$ & $4,07 \mathrm{a}$ & $8,63 \mathrm{a}$ & $0,105 \mathrm{a}$ & $92,03 \mathrm{a}$ \\
\hline $\mathrm{CV}(\%)$ & 9,05 & 3,43 & 11,29 & 23,18 & 20,69 \\
\hline
\end{tabular}

*Médias seguidas pela mesma letra nas colunas não diferem entre si ao nível de $5 \%$ de probabilidade pelo teste Tukey.

Apesar de haver, em termos absolutos, uma tendência de frutos advindos de plantas oriundas de sementes tratadas com $\mathrm{NaCl}$ apresentarem maior valor médio de firmeza, espessura de polpa, sólidos solúveis e índice de maturação.

Para a firmeza e espessura da polpa de fruto, foram registradas respostas quadráticas com valores máximos estimados de $25,9 \mathrm{~N}$ e 4,2 cm obtidos nos níveis de salinidade de 1,69 e 1,00 dS.m ${ }^{-1}$, respectivamente (Figura 4A e 4B).

A partir desse nível de salinidade da água houve uma redução de 2,1 e $5,3 \%$ na firmeza e espessura da polpa do fruto em relação ao nível de salinidade da água de $2,4 \mathrm{dS} . \mathrm{m}^{1}$, respectivamente.

O efeito da pressão osmótica causada pelo nível de sais na água tende a inibir a absorção de água pela planta. Thomaz et al. (2009), afirmaram que a firmeza da polpa, além de ser um atributo relacionado ao aroma e ao sabor dos frutos é importante devido ser essencial no manuseio pós-colheita, pelo fato dos frutos mais firmes serem mais resistentes a injúrias mecânicas sofridas durante $o$ transporte e a comercialização.

A espessura da polpa é uma característica que permite estimar e obter seu rendimento, demonstrando maior aproveitamento da parte comestível. Dessa forma, pode-se afirmar que, os frutos provenientes de tratamentos com sementes oriundas do osmocondicionamento e, posteriormente submetidas a diferentes níveis de salinidade não proporcionaram grande diferença entre si. Nesse sentido, a espessura da polpa acompanha o crescimento do fruto em termos de comprimento e diâmetro evidenciando uma resposta proporcional ao seu crescimento.

$\mathrm{O}$ osmocondicionamento da semente por meio do $\mathrm{NaCl}$ não alterou de forma significativa o teor de sólidos solúveis, a acidez total e o índice de maturação dos frutos (Tabela 2). O teor de sólidos solúveis é expresso como percentagem da massa da matéria fresca que, no melão é um dos indicativos de qualidade e do ponto ideal de colheita, pois os açúcares são os principais componentes solúveis medidos quando se estima os sólidos solúveis.

Independente da cultivar, o teor de sólidos solúveis encontrado na literatura deve ter teor mínimo para obtenção do sabor aceitável de $9{ }^{\circ}$ Brix. Nesse trabalho, as médias obtidas nos tratamentos ficaram abaixo desse padrão com maior valor encontrado de $8,88 \%$ no tratamento onde as sementes foram osmocondicionadas com $\mathrm{NaCl}$ (Tabela 2).

Quanto aos níveis de salinidade da água de irrigação foi encontrada uma resposta quadrática para os sólidos solúveis e acidez total da polpa dos frutos do melão com valores máximos estimados de 9,59\% e 0,107 \% de ácido cítrico nos níveis de salinidade de 0,49 e $1,75 \mathrm{dS} . \mathrm{m}^{-1}$, respectivamente. A partir desses níveis de salinidade houve uma redução de 12,1 e 4,7\% no conteúdo de sólidos solúveis e acidez total quando se elevou o nível de salinidade da água até $2,4 \mathrm{dS} . \mathrm{m}^{-1}$ (Figuras $4 \mathrm{C}$ e 4D).

Resultado contraditório foi obtido por Costa et al. (2013), trabalhando com melancia, verificaram que o efeito da salinidade influenciou o teor de sólidos solúveis da cultivar 'Shadow' em que o acréscimo nos níveis de salinidade da água de irrigação de 2,77 a $4,91 \mathrm{dS} . \mathrm{m}^{-1}$ elevou os valores de sólidos solúveis de 3,58 para 5,08\%, respectivamente.

No melão, a variação nos níveis de acidez tem pouco significado em função da baixa concentração, e a intervenção da acidez no sabor não é muito representativa. De acordo com Silva (2004), a perda de acidez é considerada como desejável em grande parte dos frutos e importante para o processo de amadurecimento, onde são provavelmente convertidos em açúcares.

No tocante ao índice de maturação registrou-se uma resposta linear decrescente com valor máximo estimado de 113,7 no nível de salinidade de $0,3 \mathrm{dS} \cdot \mathrm{m}^{-1}$ (Figura 4E). À medida que se elevou o nível de salinidade da água até 2,4 $\mathrm{dS} . \mathrm{m}^{-1}$ houve uma redução observada de $21,5 \%$ no valor dessa relação entre sólidos solúveis e acidez total da polpa dos frutos do melão.

A relação entre sólidos solúveis e acidez total também conhecida como índice de maturação é uma das formas mais utilizadas para avaliar o sabor das frutas, sendo mais representativo do que a medição isolada de açúcares ou acidez titulável, proporcionando boa ideia de equilíbrio entre essas duas variáveis (CHITARRA; CHITARRA, 2005).

Portanto, a utilização do osmocondicionamento da semente em condições de irrigação com água salina afetou a sua produção, no entanto, não interferiu nas características relacionadas a qualidade dos frutos de melão do tipo Cantaloupe nas condições do semiárido paraibano. 
Figura 4. Função de resposta ajustada para firmeza da casca, espessura da polpa, sólidos solúveis, acidez total e índice de maturação em função dos níveis de salinidade da água, Pombal, Paraíba.
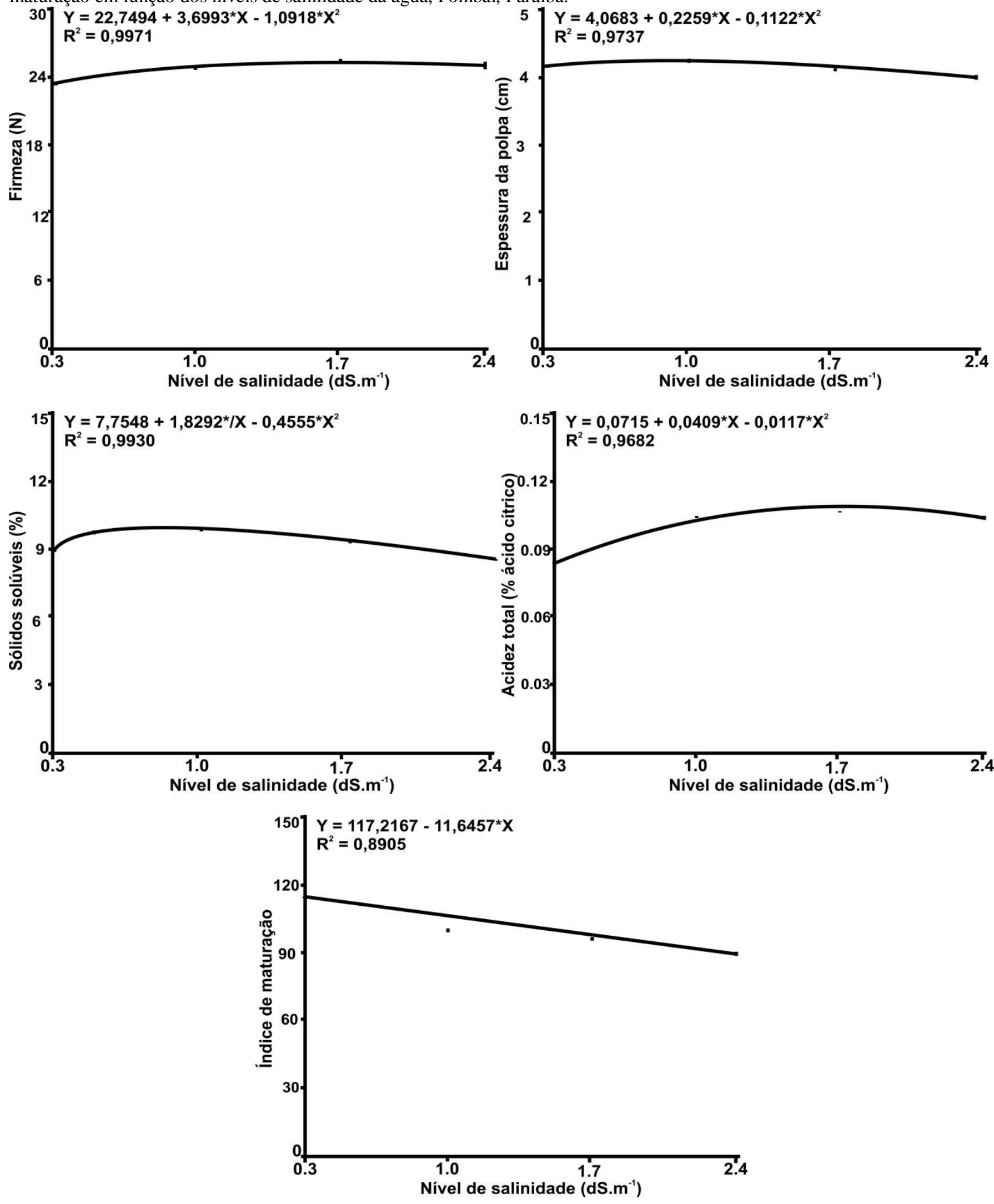

\section{CONCLUSÕES}

O osmocondicionamento das sementes em solução de $\mathrm{NaCl}$ afetou os componentes de produção do meloeiro.

A massa do fruto foi maior em plantas oriundas de sementes tratadas com $\mathrm{NaCl}$.
A massa do fruto contribuiu mais do que o número de frutos por planta para a formação da produção da planta que só foi maior em condições de baixa salinidade da água de 0,3 $\mathrm{dS} . \mathrm{m}^{-1}$.

A qualidade do fruto do meloeiro não foi alterada pelo osmocondicionamento da semente com $\mathrm{NaCl}$. 
Plantas irrigadas com água de salinidade de até 2,4 $\mathrm{dS} . \mathrm{m}^{-1}$ reduziram sua produção e qualidade de frutos de melão com menor efeito em plantas oriundas de semente tratadas com $\mathrm{NaCl}$.

\section{AGRADECIMENTOS}

Ao $\mathrm{CNPq}$ pela concessão de recurso para a realização dessa pesquisa e ao Centro de Ciências e Tecnologia Agroalimentar da Universidade Federal de Campina Grande pelo apoio em termos de recursos humanos e infraestrutura de laboratórios.

\section{REFERÊNCIAS}

BRUCE, T. J. A.; MATTHES, M. C.; NAPIER, J. A.; PICKETT, J. A. Stressful "memories" of plants: evidence and possible mechanisms. Plant Science, v. 173, n. 6, p.603-608, 2007.

CHITARRA, M. I. F.; CHITARRA, A. B. Pós-colheita de Frutos e Hortaliças: Fisiologia e manuseio. Lavras: UFLA, 2.ed. ver. e ampl. Lavras: UFLA, 2005. 785p.

COSTA, A. R. F. C.; MEDEIROS, J. F.; PORTO FILHO, F. Q.; SILVA, J. S.; COSTA, F. G. B.; FREITAS, D. C. Produção e qualidade de melancia cultivada com água de diferentes salinidades e doses de nitrogênio. Revista Brasileira Engenharia Agrícola Ambiental, v.17, n.9, p.947954, 2013.

EMBRAPA. Centro Nacional e Pesquisa em Solos. 2008. Sistema Brasileiro de Classificação de Solos. Brasília: Embrapa-SPI; Rio de Janeiro: Embrapa-Solo, 2. ed. Brasília: Embrapa-SPI; Rio de Janeiro: Embrapa-Solo. 306p.

FREITAS, L. D. A.; FIGUEIRÊDO, V. B.; PORTO FILHO, F. Q.; COSTA, J. C.; CUNHA, E. M. 2014. Crescimento e produção do meloeiro cultivado sob diferentes níveis de salinidade e nitrogênio. Revista Brasileira Engenharia Agrícola Ambiental, v.18, (Suplemento), p.20-26, 2014.

LIMA, L. B.; MARCOS FILHO, J. Condicionamento fisiológico de sementes de pepino e relação com desempenho das plantas em campo. Revista Brasileira de Sementes, v.31, n.3, p.27-37, 2009.

MEDEIROS, D. C.; MEDEIROS, J. F.; PEREIRA, F. A. L.; SOUZA, R. O.; SOUZA, P. A. Produção e qualidade de melão cantaloupe cultivado com água de diferentes níveis de salinidade. Revista Caatinga, v.24, n.1, p. 92-98, 2011.

NASCIMENTO NETO, J. R.; BOMFIM, G. V.; AZEVEDO, B. M.; VIANA, T. V. A.; VASCONCELOS, D. V. Formas de aplicação e doses de nitrogênio para o meloeiro amarelo no litoral do Ceará. Irriga, v.17, n.3, p.364-375,2012.

PACHECO, M. V.; FERRARI, C. E. S.; BRUNO, R. L. A.; ARAÚJO, F. S.; SILVA, G. Z.; ARRUDA, A. A. Germinação e vigor de sementes de Capparis flexuosa L. submetidas ao estresse salino. Revista Brasileira de Ciências Agrárias, v.7, n.2, p. 301-305, 2012.
PEREIRA, A. M.; QUEIROGA, R. C. F.; SILVA, G. D.; NASCIMENTO, M. G. R.; ANDRADE, S. E. O. Germinação e crescimento inicial de meloeiro submetido ao osmocondicionamento da semente com $\mathrm{NaCl}$ e níveis de salinidade da água. Revista Verde de Agroecologia e desenvolvimento Sustentável, v.7, n.3, p.205-211, 2012.

PINHEIRO, D. T. Estresse salino no potencial fisiológico de sementes e no desenvolvimento vegetativo de melão (Cucumis melo L.), 2015. 61 f. Tese (Doutorado em Fitotecnia), Programa de Pós-Graduação em Fitotecnia, Universidade Federal de Viçosa, Viçosa, 2015.

QUEIROGA, R. C. F.; ANDRADE NETO, R. C.; NUNES, G. H. S.; MEDEIROS, J. F.; ARAÚJO, W. B. M. Germinação e crescimento inicial de híbridos de meloeiro em função da salinidade. Horticultura Brasileira, v. 24, n.3, p.315-319, 2006.

SILVA, M. C. C.; MEDEIROS, J. F.; NEGREIROS, M. Z.; SOUSA, V. F. Produtividade de frutos do meloeiro sob diferentes níveis de salinidade da água de irrigação, com e sem cobertura do solo. Horticultura Brasileira, v.23, n.2, p.202-205, 2005.

SILVA, M. V. T.; SOUSA LIMA, R. M.; OLIVEIRA, F. L.; SILVA, N. K. C.; MEDEIROS, J. F. Produção de abobora sob diferentes níveis de água salina e doses de nitrogênio. Revista Verde de Agroecologia e Desenvolvimento Sustentável, v.9, n.1, p.287-294, 2014.

SILVA, P. S.; MENEZES, J. B.; OLIVEIRA, O. F.; SILVA, P. I. B. Distribuição do Teor de Sólidos Solúveis Totais no Melão. Horticultura Brasileira, v.21, n.1, p.31-33, 2003.

SIQUEIRA, W. C.; FARIA, L. A.; LIMA, E. M. C.; REZENDE, F. C.; GOMES, L. A. A.; CUSTÓDIO, T. N. Qualidade de frutos de melão amarelo cultivado em casa de vegetação sob diferentes lâminas de irrigação. Ciência e Agrotecnologia, v.33, n.4, p.1041-1046, 2009.

SIVITREPE, N.; SIVITREPE, H. O.; ERIS, A. The effect of $\mathrm{NaCl}$ priming on salt tolerance in melon seedling grown under saline conditions. Scientiae Horticulturae, v. 97, n. 3-4, p. $229-237,2003$.

TERCEIRO NETO, C. P. C.; GHEYI, H. R.; MEDEIROS, J. F.; DIAS, N. S.; CAMPOS, M. S. Produtividade e qualidade de melão sob manejo com água de salinidade crescente. Pesquisa Agropecuária Tropical, v.43, n.4, p.354-362, 2013.

TOMAZ, H. V. Q.; AROUCHA, E. M. M.; NUNES, G. H. S.; BEZERRA NETO, F.; TOMAZ, H. V. Q.; QUEIROZ, R. F. Qualidade pós-colheita de diferentes híbridos de melão Amarelo armazenados sob refrigeração. Revista Brasileira de Fruticultura, v. 31, n.4, p.25-32, 2009. 